\title{
Review
}

\section{The impact of microplastic pollution on ecological environment: a review}

\author{
Xi Mao ${ }^{1,2, *}$, Yuchen $\mathrm{Xu}^{2}$, Zhong Cheng ${ }^{2}$, Yunbo Yang ${ }^{2}$, Zetang Guan² ${ }^{2}$ Lu Jiang ${ }^{2}$, Kai Tang ${ }^{2}$ \\ ${ }^{1}$ School of Civil Engineering and Architecture, Wuyi University, 354300 Wuyishan, Fujian, China \\ ${ }^{2}$ College of Water Conservancy and Hydropower Engineering, Sichuan Agricultural University, 625014 Yaan, Sichuan, China \\ *Correspondence: maowhiteknight@163.com (Xi Mao) \\ Academic Editor: Kevin Cianfaglione \\ Submitted: 22 September 2021 Revised: 24 November 2021 Accepted: 8 December 2021 Published: 26 January 2022
}

\begin{abstract}
Microplastic pollution and its impact on the ecological environment have attracted worldwide attention. The strong adsorption capacity of the microplastic surface plays an important role in the migration of microplastics throughout the environment. Synergistic effects between microplastics and persistent organic pollutants increase the toxicity of pollutants to organisms. In addition, microplastics cause different degrees of harm to aquatic organisms with different nutritional levels. However, the toxic effects of microplastics and organic pollutants on organisms, the distribution of microplastics in higher aquatic organisms, and the nutrient transfer in complex aquatic food webs require further research. Therefore, studying the impact of microplastics on the ecological environment would provide insights into controlling microplastic pollution. This paper in-depth discusses the source, distribution, and transmission of microplastics and summarizes the current situation of the impact of microplastics on the ecological environment, including physical, chemical, and biological effects. This paper also suggests topics for further research on the influence of microplastics on various aspects of the ecological environment.
\end{abstract}

Keywords: Aquatic organism; Ecological environment; Microplastic; Microplastic pollution; Water environment

\section{Introduction}

Microplastic pollution has become a global environmental problem, and many scholars have studied the toxicity of microplastics. When microplastics enter organisms, microplastics threaten biological health through oxidative stress, nerve injury, endocrine disruption, immune injury, and other mechanisms. Additionally, when microplastics exist in the environment, under certain conditions, the interaction between microplastics and persistent organic pollutants has uncertain effects on organisms, most of which are harmful. When plastic products manufactured and discarded by human beings enter the ecological environment, the harm to organisms may affect human beings through the food chain.

With the increasing amount of microplastics entering the ecological environment, the control of microplastic pollution has substantial significance for environmental protection and species protection.

Microplastics are plastic particles with a diameter of less than $5 \mathrm{~mm}$. Due to the wide existence of microplastics in the ecological environment and various determined and uncertain hazards to organisms, microplastics have received extensive attention from a wide range of research fields. Microplastics can exist in the environment for hundreds of years because of their stable chemical properties [1]. At present, most plastics are low-density polyethylene (LDPE), high-density polyethylene (HDPE), polypropylene (PP), polystyrene (PS), polyethylene tetraacetate (PET), and polyvinyl chloride (PVC). Sources of mi- croplastics are divided into primary and secondary sources [2]. Primary sources are mainly plastic particles in personal care products and cosmetics. Secondary sources are microplastics derived from the physical, chemical, and biodegradation of large plastics. Surface runoff, wastewater from sewage treatment plants, aquaculture and fishery, dumping of household and industrial wastes, and atmospheric emissions into the ocean are reasons for microplastics that enter the ecological environment [3].

These widely distributed microplastics threaten marine organisms. Plastics of different colors, volumes, and shapes exist in the water environment [4]. Because their small density, light volume, and particle size are similar to the food of many marine organisms, microplastics are eaten by or adsorbed on marine organisms after entering the water and accumulate in their gastrointestinal organs and tissues, threatening their health [5]. High-nutrient organisms accumulate microplastics by eating low-nutrient organisms whose bodies have accumulated microplastics [6]. After entering organisms, microplastics harm them through different mechanisms. Human consumption of fish containing microplastics may result in microplastics entering the human body, posing an unknown threat to human health and, ultimately, affecting biodiversity.

Persistent organic pollutants are common in the ecological environment. Because of the adsorption characteristics of microplastics, they interact with adsorbed persistent organic pollutants, resulting in compound toxicity, indirectly affecting organisms. The advantages and disadvan- 
tages of this interaction for biological effects are unknown, and under certain circumstances, this interaction may benefit organisms. Additionally, microplastics can be used as a carrier of persistent organic pollutants such that they migrate to the ocean and threaten marine organisms.

\section{Microplastic distribution}

Plastic waste enters the natural environment after its degradation into smaller particles due to photooxidation, weathering, and mechanical and biological degradation, resulting in microplastics [7]. Microplastics are difficult for organisms to digest and decompose, which allows them to spread throughout the global food chain. The closer an organism is to the top of the food chain, the higher its content of microplastics; thus, this phenomenon seriously endangers human health. Studies have demonstrated the existence of microplastics in plankton, fish, and seabirds [8,9].

With the wide use of plastics and the transfer of food chains, microplastic pollution has become a global environmental problem. For example, Wang et al. [10] demonstrated that the Wuliangsu Sea in northwest China contained microplastics with an abundance ranging from (1.76 \pm $0.71)$ to $(10.12 \pm 4.09) \mathrm{nL}^{-1}$. After sampling and analyzing the sediments from 72 sedimentary sites in the Bohai Sea and the Yellow Sea in eastern China, the researchers found that the sediments contained a small amount of microplastics, and the particle size was between 66.25 and 4982.59 $\mu \mathrm{m}$ [11]. In the Caspian coastal environment, the pollution of microplastics varies in the number of microplastics [12]. Microplastic pollution is common in various environments of the Bristol Strait beach, United Kingdom [13].

The influence of the ocean current and atmospheric circulation causes dynamic changes in the abundance and distribution characteristics of microplastics in the marine environment. Studies have not found microplastics in the surface waters of Antarctic coastal waters less affected by human activities [14]. However, in a subsequent study, the researchers investigated and analyzed the average abundance of microplastics in lateral Antarctic fish near the South Shetland Islands, which is $(0.36 \pm 0.51) \mathrm{n} / \mathrm{n}$ and has been slightly polluted [15]. These research conclusions show that the distribution of microplastics has spread to various world regions and has gradually become a serious global pollution problem. Research on the distribution characteristics of microplastics has focused on the spatial and temporal variation characteristics of surface sediments, not vertical distribution characteristics. Microplastics are buried in the deep sea due to wind, tides, waves, and other external forces. The complex environment in water and the activities of aquatic organisms also make the vertical distribution of microplastics complex and dynamic. Fibers and microplastics are easily attached by organisms and settled to the seabed. Studies have shown that the vertical movement of microplastics substantially influences the size and abundance distribution of microplastics [16]. Cheng et al.
[17] conducted a continuous seasonal survey in the coastal zone of Yantai and found that the microplastics in the water migrated between the surface water, the water, and seabed sediments through diffusion, suspension and resuspension, settlement, and burial; in their research area, the content of microplastics in the surface water was significantly higher than that in the bottom water.

\section{The mechanism of microplastics affecting biology}

\subsection{Oxidative stress}

Microplastics can break the dynamic balance of normal redox by affecting the activity of antioxidant enzymes in vivo, resulting in the oxidative damage of biological macromolecules and interfering with normal life activities.

Microplastics cause oxidative stress in organisms, which can lead to cell damage and cell membrane structure damage, resulting in a decrease in cell membrane permeability, affecting the normal physiological process of cells (e.g., reducing cell growth rate and fecundity). Isocitrate dehydrogenase (IDH) is essential to maintain the redox balance of cells. Microplastics can inhibit the activity of IDH, leading to oxidative stress and muscle injury in organisms [18]. Photoautotrophic organisms (e.g., algae and cyanobacteria) are the basis of aquatic food networks, which are crucial to aquatic ecosystems. Algae exposed to nanoparticles has been observed to inhibit the photosynthesis of algae and begin to produce reactive oxygen species (ROS). The intake and accumulation of microplastics increase the ROS content in algae cells, leading to oxidative stress in algae cells [19].

\subsection{Neurological damage}

Inhibition of acetylcholinesterase (AchE) was found in various organisms exposed to microplastics. It can also be thought of as hindering neuronal function and may decrease neuronal network function [20]. AchE dissolves acetylcholine $(\mathrm{ACH})$ into choline and acetic acid, which are crucial to the normal function of the nervous system [21]. AchE is often used as a biomarker in experiments to determine whether the experimental target causes neurotoxicity. For example, after black crucian carp larvae ate polystyrene microplastics $[(24.7 \pm 0.2) \mathrm{nm}]$, their brain tissue showed swelling and low activity [22]. Oliveira et al. [23] studied the impact of polyethylene (PE) microplastic particles on marine organisms, the larvae of Pomatoschistus microps were exposed to a solution of $184 \mu \mathrm{g} / \mathrm{L}$ PE microplastics (1$5 \mu \mathrm{m})$, the results indicate that the particles inhibited the activity of AchE, leading to the blocking of neurotransmitter transfer in fish and ultimately affecting nerve function.

\subsection{Endocrine disruption}

In modern industrial production, plastic synthesis and processing add organic and inorganic components to plastic to expand the efficiency of the final plastic product. Chem- 
icals such as phthalates, polybrominated diphenyl ethers, and bisphenol $\mathrm{A}$ are added to plastics as plasticizers, flame retardants, stabilizers, and fungicides. These substances can thus be used as endocrine disruptors, causing serious endocrine-disrupting effects in development and reproduction [24]. Phthalates and bisphenol A can destroy the thyroid function of amphibians and affect larval development [25]. Moreover, phthalates can cause endocrine disruption in fish by affecting the signaling pathway that targets the nuclear hormone receptorand possibly destroying their endocrine regulation $[26,27]$.

\subsection{Immune injury}

After biological intake, microplastics can enter the immune system through their accumulation and transfer in tissues and organs and interfere with immune response. Microplastics can interfere with the natural defense mechanism of fish and can be a stress source. Therefore, the entry of microplastics into fish can lead to reduced phagocytic activity of immune cells, reduced cell viability, and destruction of the lysosome membrane [28]. Microplastic exposure may also cause inflammation and affects the activation of pro-inflammatory cytokines. Microplastics can affect the release of cytokines or changes in inflammatory response genes in in vitro cell line models [29].

\section{Interaction between microplastics and organic pollutants}

Microplastics are a primary source of pollutants in the ocean, are toxic, and have a surface with a strong adsorption capacity. Mato et al. [30] found that the main source of toxic chemicals in the ocean is the adsorption of organic pollutants by plastic additives or their degradation products. Therefore, microplastics can be used as a carrier of persistent organic pollutants and transmitted to oceans worldwide, harming marine organisms.

\subsection{Adsorption of organic pollutants by microplastics}

Adsorption of organic pollutants by microplastics is a notable interaction. Xu et al. [31] found that microplastics could be used as the carrier of sulfate in a water environment. Li et al. [32] found that polyamide particles, which are frequently observed in water environments, can be used as carriers of antibiotics. Rochman et al. [33] found complex metal mixtures on plastic fragments composed of various plastic types. These studies show that microplastics have an adsorption effect on organic pollutants in the environment. Moreover, the type, particle size, and aging degree of microplastics affect the adsorption of organic pollutants. Different types of microplastics have different adsorption capacities for organic pollutants. Wang et al. [34] studied the adsorption effect of PE and nylon fiber on hydrophobic (phenylpropene) and hydrophilic (phenol) organic pollutants; the results showed that the adsorption capacity of PE was approximately 1-2 orders of magnitude higher than that of nylon fiber, indicating the importance of surface functional groups (with or without hydrophilic groups) for plastics. The adsorption process of a polymer is closely related to its particle size. Zhang et al. [35] studied the adsorption of 3,6-dibromocarbazole and 1,3,5,6,8-tetrabromocarbazole on polypropylene microplastics with different particle sizes in simulated seawater; they found that the adsorption capacity of microplastics increased with the decrease in particle size. Napper et al. [4] found that rough particles of pollutants were easier to adsorb than smooth particles; they used adsorption experiments of $\mathrm{PE}$ on binary mixtures of organochlorine pesticide bis-p-chlorophenyltrichloroethane (C-DDT) and H-phenylpropene. The aging degree of microplastics influences their adsorption capacity. Alimi et al. [36] found that aged microplastics adsorb more PCBs than unaged microplastics. In addition, there are a variety of adsorption mechanisms in the process of microplastic adsorption of organic pollutants, and the degree of influence of various adsorption mechanisms is jointly determined by the properties of plastic, water environment and organic pollutants.

\subsection{Transport of organic pollutants by microplastics}

Microplastics in the environment easily migrate, diffuse, and redistribute globally because of their small particle size, stable chemical properties, and hydrophobicity. Microplastics play a notable role in the transportation of pollutants, especially hydrophobic microplastics [37]. JAVIER et al. [38] studied the adsorption of polychlorinated biphenyls (PCBs) by microplastics; the results showed that the adsorption process was reliable and repeatable for the samples of double distilled water and treated urban sewage, indicating that there were different interactions between organic pollutants and plastics. Wang et al. [34] demonstrated that a high abundance of plastic fibers can lead to a higher pollutant transfer effect than marine sediments. In the study of the interaction between microplastics and freshwater microalgae by Lagarde et al. [39], microplastics colonized and aggregated rapidly by microalgae, which may lead to changes in the buoyancy of polymers. Therefore, the amount of sedimentation of polymers and microplastics differs due to the chemical properties of microplastics, resulting in different transport routes and uneven distribution. The transport routes of microplastics to the water environment include surface runoff, river inflow, sewage discharge, and shipping et cetera. In recent years, the amount of microplastics in rivers has increased year by year, and the prevention and control of microplastics have also been extended from the ocean to the inland. Surface runoff and river inflow are the main ways for the migration of inland pollutants. Meanwhile, rainfall is the most direct factor to form surface runoff. Therefore, rainfall is a major environmental factor for microplastic pollution in inland waters. Xia et al. [40] proved the close relationship between rainfall and microplastic abundance in the rainfall 
on East Lake: the abundance of microplastics changed significantly and was significantly affected by rainfall.

\subsection{Joint toxicity of microplastics and persistent organic pollutants}

Microplastics contain toxic substances. Lambert et al. [41] found that the ecological toxicity of microplastics may be related to their physical and chemical properties, including particle size, particle shape, crystal, polymer, and additive components. Microplastics can cause disorders of the intestinal flora, destroying the ratio of probiotics and pathogenic bacteria [42]. Fish intake of microplastic debris at a certain concentration of organic pollutants may damage the endocrine system function of adult fish [43]. Studies have shown that microplastic organic pollutants can be deoxygenated in the intestine of fish [44]. Obviously, microplastics do have toxic effects on organisms.

After microplastics adsorb organic pollutants, the two interact. Studies, for example, Giacomo et al. [45] have shown that microplastics can adsorb polycyclic aromatic hydrocarbons, highlighting the high bioavailability of these chemicals after intake and the toxicological effects of multiple molecular and cellular pathways on microplastics. Studies have also found that when microplastics are exposed to low concentrations (e.g., $2 \mathrm{ug} / \mathrm{L}$ ) of $17 \alpha$-ethylenediethylene glycol (EE2), the inhibitory effect of EE2 on zebrafish movement is reduced because of the decrease in free dissolved EE2 concentration. However, when the concentration of EE2 is increased to $20 \mathrm{ug} / \mathrm{L}$, EE2 and microplastics show a strong destructive effect on zebrafish [46]. The findings of these studies show that synergistic or antagonistic effects occur when microplastics adsorb persistent organic pollutants.

\section{Potential effects of microplastic pollution}

\subsection{Potential effects of microplastics on organisms}

Data show that microplastics exist in air, drinking water, and food, which are essential for human survival. Microplastics floating in the air enter the human respiratory system through breathing. The intake of food and drinking water containing microplastics transports microplastics into the human digestive system [47-49]. Results showed that the number of microplastics entering the human body through salt, drinking water, and breathing was $(0-7.3) \times$ $10^{4},(0-4.7) \times 10^{3}$, and $(0-3.0) \times 10^{7}$ per person per year, respectively [50]. Although the impact of microplastics on human health remains unclear, researchers have generally posited that microplastics have a potential negative impact on human health [51]; for example, microplastics can penetrate the lungs. Furthermore, frequent contact may cause adverse symptoms in the respiratory system and increase the carcinogenic rate [52].

In agriculture, the extensive use of chemical fertilizers and plastic films containing microplastics has caused the microplastic content in agricultural soil to exceed that in the marine environment [53]. However, the study of plant ecotoxicological effects of microplastics remains in the preliminary stage [54]. Only a few investigations have demonstrated the effects of microplastics on plants such as mung bean [55], wheat [56,57], and soybean [58]. Studies have shown that di (2 - ethyl hexyl) phthalate (DEHP) in PVC agricultural film can be precipitated in large quantities under weak acidic conditions [59], resulting in potential toxicological effects on plants. Liu et al. [60] found that plasticizers in plastics (phthalate esters) can inhibit the germination of wheat seeds and cause programmed cell death of wheat seeds at high concentrations $\left(1500-1800 \mathrm{mg} \cdot \mathrm{L}^{-1}\right)$. In addition, the surface of weathered microplastics in the environment is rough and has a large specific surface area and negative charge [61,62], which can adsorb heavy metals and organic pollutants, becoming the environmental carrier of pollutants and having a certain impact on plants. Therefore, the combined effect of microplastics and heavy metals or pesticides in agricultural systems requires further research. In addition, Giorgetti et al. [63] reported that $50 \mathrm{~nm}$ polystyrene nanoplastics could be internalized in onion root division cells, causing oxidative stress, cytotoxicity (e.g., mitotic abnormality), and gene toxicity. Therefore, studying the types and particle sizes of microplastics is essential to revealing the plant toxicity of microplastics.

\subsection{Potential effects of microplastics on the ecological environment}

The amount of plastic fibers found deposited in the air of France is $2-355 /\left(\mathrm{d} \cdot \mathrm{m}^{2}\right)$, with an average of 0.9 plastic fibers per $\mathrm{m}^{3}$ outdoor air $[64,65]$. Microplastics in the above air can enter the marine environment. At present, although indoor toxicological experiments have demonstrated that microplastics can produce various toxic effects on organisms, the concentration of microplastics used in those experiments is much higher than that in the real environment. Therefore, whether microplastics harm the ecosystem in low concentrations in the real environment remains unknown. Notably, many studies have shown that microplastics can be enriched along the food chain through aquatic products and salt.

Plastic degradation in soils is slow because of the lack of sun exposure and mechanical wear [66]. These microplastics can continue to accumulate in the soil and form a sink of microplastics in the soil. Because microplastics are surrounded by soil particles or combined with soil aggregates, they may affect soil bulk density, permeability, water holding capacity, and water stability agglomeration in soil [67]. Anderson et al. [68] studied the effects of four types of microplastics (e.g., PP and PET) on bulk density, water holding capacity, and water stability agglomeration of sandy soil and found that only PET had a negative correlation between soil bulk density and water stability agglomeration, and other types of microplastics had no effect. However, Zhang et al. [69] demonstrated a different result: 
PET had a negative impact on soil water holding capacity and had no effect on soil bulk density [70]. This difference may be due to the use of different soil physicochemical properties in the experiment. In addition, microplastics may change soil porosity through permeability or affect soil permeability and further affect water evaporation in soil. Due to the lack of research on this aspect, further exploration is needed to fully verify the above theories.

\section{Conclusions}

The study of microplastic pollution has attracted worldwide attention. Despite the progress made in some aspects, many problems require further research.

(1) Establishing a standard method for measuring microplastics is necessary. Because, on the one hand, in the distribution of microplastics, different sampling methods affect the vertical and horizontal distribution results of microplastics in the ocean. Uniform standards should therefore be adopted for sampling. On the other hand, because of the diversity of plastic types, shapes, and diameters, and their wide distribution in different environments, the methods used in the literature differ from the sampling and analysis methods; this difference in methods has profoundly affected the comparability between studies.

(2) The joint pollution effects of microplastics and other environmental pollutants deserve further study. Because, for example, plastic synthesis and processing are added to plastic organic and inorganic components to expand the effectiveness of the final plastic products, and microplastics usually contain additives or monomers. Furthermore, microplastics can adsorb heavy metals, organic pollutants, and other pollutants. Therefore, in all environmental compartments, plastic debris is highly likely to be associated with the exchange of other pollutants. Hence, the toxicity of microplastics is mostly compound toxicity that requires comprehensive study by combining its components.

(3) The separation and removal technology of microplastics in the wastewater discharge system deserve further study. Because, at present, the main treatment methods of microplastics are incineration and landfill, but many microplastics enter the water environment through the urban sewage discharge system, and there is no specific removal process for microplastics in the water environment. According to the existing law of microplastics in the wastewater discharge system, the related technologies can be reasonably enhanced to improve the removal rate of microplastics under the premise of ensuring the standard of wastewater treatment.

(4) Microplastics in soil are mostly caused by large quantities of waste packaging (e.g., agricultural films, plastic films, pesticides, and fertilizers used in agricultural production) and easily decompose into microplastics due to natural or human behavior (e.g., improper recycling). Because of the soil pollution caused by such behaviors, gov- ernments should pass relevant laws and advocate that individuals care for the environment and not discard plastic products. Additionally, enterprises can be subsidized to encourage the development of environmentally friendly plastic products.

\section{Author contributions}

$\mathrm{XM}$ is responsible for writing, editing, and reviewing the whole paper; YX and ZC participated in the 2nd, 3rd, and 6th parts; YY and ZG participated in the 4th part; LJ and KT participated in the 5 th part.

\section{Ethics approval and consent to participate}

Not applicable.

\section{Acknowledgment}

Not applicable.

\section{Funding}

This work was supported by Education Department of Sichuan Province (grant number: 035Z1994).

\section{Conflict of interest}

The authors declare no conflict of interest.

\section{References}

[1] Hidalgo-Ruz V, Gutow L, Thompson RC, Thiel M. Microplastics in the Marine Environment: a Review of the Methods used for Identification and Quantification. Environmental Science \& Technology. 2012; 46: 3060-3075.

[2] Auta HS, Emenike CU, Fauziah SH. Distribution and importance of microplastics in the marine environment: a review of the sources, fate, effects, and potential solutions. Environment International. 2017; 102: 165-176.

[3] Talvitie J, Mikola A, Setälä O, Heinonen M, Koistinen A. How well is microlitter purified from wastewater?-A detailed study on the stepwise removal of microlitter in a tertiary level wastewater treatment plant. Water Research. 2016; 109: 164-172.

[4] Napper IE, Bakir A, Rowland SJ, Thompson RC. Characterisation, quantity and sorptive properties of microplastics extracted from cosmetics. Marine Pollution Bulletin. 2015; 99: 178-185.

[5] Akhbarizadeh R, Moore F, Keshavarzi B. Investigating microplastics bioaccumulation and biomagnification in seafood from the Persian Gulf: a threat to human health? Food Additives \& Contaminants. Part A, Chemistry, Analysis, Control, Exposure \& Risk Assessment. 2019; 36: 1696-1708.

[6] Nelms SE, Galloway TS, Godley BJ, Jarvis DS, Lindeque PK. Investigating microplastic trophic transfer in marine top predators. Environmental Pollution. 2018; 238: 999-1007.

[7] Cole M, Lindeque P, Halsband C, Galloway TS. Microplastics as contaminants in the marine environment: a review. Marine Pollution Bulletin. 2011; 62: 2588-2597.

[8] Hoffmann L, Eggers SL, Allhusen E, Katlein C, Peeken I. Interactions between the ice algae Fragillariopsis cylindrus and microplastics in sea ice. Environment International. 2020; 139: 105697.

[9] Xie YS, Zhang QK, Zhang LS, Zhong S, Liu JY, Hou XY, et al. Impact of a Sewage Treatment Plant on the Accumulation of Microplastics in Freshwater Organisms in the Lijiang River 
of the Guilin Urban Section. Environmental Science. 2020; 41: 4999-5007. (In Chinese)

[10] Wang Z, Qin Y, Li W, Yang W, Meng Q, Yang J. Microplastic contamination in freshwater: first observation in Lake Ulansuhai, Yellow River Basin, China. Environmental Chemistry Letters. 2019; 17: 1821-1830.

[11] Liu T, Sun XX, Zhu ML, Ling JH, Zhao YF. Distribution and composition of microplastics in the surface water of the east china sea. Oceanologia et Limnologia Sinica. 2018; 49: 62-69. (In Chinese)

[12] Nematollahi MJ, Moore F, Keshavarzi B, Vogt RD, Nasrollahzadeh Saravi H, Busquets R. Microplastic particles in sediments and waters, south of Caspian Sea: Frequency, distribution, characteristics, and chemical composition. Ecotoxicology and Environmental Safety. 2020; 206: 111137.

[13] Kor K, Ghazilou A, Ershadifar H. Microplastic pollution in the littoral sediments of the northern part of the Oman Sea. Marine Pollution Bulletin. 2020; 155: 111166.

[14] Kuklinski P, Wicikowski L, Koper M, Grala T, Leniec-Koper H, Barasiński M, et al. Offshore surface waters of Antarctica are free of microplastics, as revealed by a circum-Antarctic study. Marine Pollution Bulletin. 2019; 149: 110573.

[15] Gao CM, Cao Z, Yan CB, Zhu GP. Microplastic characteristics and distribution of gastrointestinal contents of striped Antarctic fish in the waters around the South Shetland Islands, Antarctica. Journal of Fisheries of China. 2021; 1-9. (In Chinese)

[16] Desforges JW, Galbraith M, Dangerfield N, Ross PS. Widespread distribution of microplastics in subsurface seawater in the NE Pacific Ocean. Marine Pollution Bulletin. 2014; 79: 94-99.

[17] Cheng JJ, Li YF, Zhou T, Tang C. Study on pollution characteristics of micro plastics in Yantai coastal zone. Environmental Protection. 2020; 48: 47-52. (In Chinese)

[18] Barboza LGA, Vieira LR, Branco V, Figueiredo N, Carvalho F, Carvalho C, et al. Microplastics cause neurotoxicity, oxidative damage and energy-related changes and interact with the bioaccumulation of mercury in the European seabass, Dicentrarchus labrax (Linnaeus, 1758). Aquatic Toxicology. 2018; 195: 4957.

[19] Moos N, Slaveykova VI. Oxidative stress induced in bacteria and aquatic microalgae -state of the art and knowledge gaps. Nanotoxicology. 2014; 8: 605-630.

[20] Keefer EW, Norton SJ, Boyle NAJ, Talesa V, Gross GW. Acute Toxicity Screening of Novel AChE Inhibitors Using Neuronal Networks on Microelectrode Arrays. NeuroToxicology. 2001; 22: 3-12.

[21] Massoulié J, Pezzementi L, Bon S, Krejci E, Vallette FM. Molecular and cellular biology of cholinesterases. Progress in Neurobiology. 1993; 41: 31-91.

[22] Mattsson K, Ekvall MT, Hansson L, Linse S, Malmendal A, Cedervall T. Altered behavior, physiology, and metabolism in fish exposed to polystyrene nanoparticles. Environmental Science \& Technology. 2015; 49: 553-561.

[23] Oliveira M, Ribeiro A, Hylland K, Guilhermino L. Single and combined effects of microplastics and pyrene on juveniles $(0+$ group) of the common goby Pomatoschistus microps (Teleostei, Gobiidae). Ecological Indicators. 2013; 34: 641-647.

[24] Hahladakis JN, Velis CA, Weber R, Iacovidou E, Purnell P. An overview of chemical additives present in plastics: Migration, release, fate and environmental impact during their use, disposal and recycling. Journal of Hazardous Materials. 2018; 344: 179199.

[25] Oehlmann J, Schulte-Oehlmann U, Kloas W, Jagnytsch O, Lutz $\mathrm{I}$, Kusk KO, et al. A critical analysis of the biological impacts of plasticizers on wildlife. Philosophical Transactions of the Royal Society of London. Series B, Biological Sciences. 2009; 364 :
2047-2062.

[26] Lang IA, Galloway TS, Scarlett A, Henley WE, Depledge M, Wallace RB, et al. Association of urinary bisphenol a concentration with medical disorders and laboratory abnormalities in adults. The Journal of the American Medical Association. 2008; 300: $1303-1310$.

[27] Kim E, Kim J, Lee S. Inhibition of oocyte development in Japanese medaka (Oryzias latipes) exposed to di-2-ethylhexyl phthalate. Environment International. 2002; 28: 359-365.

[28] Sharifinia M, Bahmanbeigloo ZA, Keshavarzifard M, Khanjani $\mathrm{MH}$, Lyons BP. Microplastic pollution as a grand challenge in marine research: a closer look at their adverse impacts on the immune and reproductive systems. Ecotoxicology and Environmental Safety. 2020; 204: 111109.

[29] Hu M, Palić D. Micro- and nano-plastics activation of oxidative and inflammatory adverse outcome pathways. Redox Biology. 2020; 37: 101620

[30] Mato Y, Isobe T, Takada H, Kanehiro H, Ohtake C, Kaminuma T. Plastic resin pellets as a transport medium for toxic chemicals in the marine environment. Environmental Science \&Amp; Technology. 2001; 35: 318-324.

[31] Xu B, Liu F, Brookes PC, Xu J. The sorption kinetics and isotherms of sulfamethoxazole with polyethylene microplastics. Marine Pollution Bulletin. 2018; 131: 191-196.

[32] Li J, Zhang K, Zhang H. Adsorption of antibiotics on microplastics. Environmental Pollution. 2018; 237: 460-467.

[33] Rochman CM, Hentschel BT, Teh SJ. Long-term sorption of metals is similar among plastic types: implications for plastic debris in aquatic environments. PLoS ONE. 2014; 9: e85433.

[34] Wang Z, Chen M, Zhang L, Wang K, Yu X, Zheng Z, et al. Sorption behaviors of phenanthrene on the microplastics identified in a mariculture farm in Xiangshan Bay, southeastern China. The Science of the Total Environment. 2018; 628-629: 1617-1626.

[35] Zhang GS, Zhang FX, Li XT. Effects of polyester microfibers on soil physical properties: Perception from a field and a pot experiment. The Science of the Total Environment. 2019; 670: $1-7$.

[36] Alimi OS, Farner Budarz J, Hernandez LM, Tufenkji N. Microplastics and Nanoplastics in Aquatic Environments: Aggregation, Deposition, and Enhanced Contaminant Transport. Environmental Science \& Technology. 2018; 52: 1704-1724.

[37] Wu C, Zhang K, Huang X, Liu J. Sorption of pharmaceuticals and personal care products to polyethylene debris. Environmental Science and Pollution Research International. 2016; 23 : 8819-8826.

[38] Bayo J, Olmos S, Sánchez E, Roca MJ, Guillén M, Jiménez P. Microplastics as vector for persistent organic pollutants in urban effluents: the role of Polychlorinated Biphenyls. International Journal of Sustainable Development and Planning. 2018; 13: $671-682$.

[39] Lagarde F, Olivier O, Zanella M, Daniel P, Hiard S, Caruso A. Microplastic interactions with freshwater microalgae: Heteroaggregation and changes in plastic density appear strongly dependent on polymer type. Environmental Pollution. 2016; 215: 331-339.

[40] Xia W, Rao Q, Deng X, Chen J, Xie P. Rainfall is a significant environmental factor of microplastic pollution in inland waters. Science of the Total Environment. 2020; 732: 139065.

[41] Lambert S, Scherer C, Wagner M. Ecotoxicity testing of microplastics: Considering the heterogeneity of physicochemical properties. Integrated Environmental Assessment and Management. 2017; 13: 470-475.

[42] Fackelmann G, Sommer S. Microplastics and the gut microbiome: how chronically exposed species may suffer from gut dysbiosis. Marine Pollution Bulletin. 2019; 143: 193-203.

[43] Rochman CM, Kurobe T, Flores I, Teh SJ. Early warning signs 
of endocrine disruption in adult fish from the ingestion of polyethylene with and without sorbed chemical pollutants from the marine environment. The Science of the Total Environment. 2014; 493: 656-661.

[44] Batel A, Linti F, Scherer M, Erdinger L, Braunbeck T. Transfer of benzo $[\alpha]$ pyrene from microplastics to Artemia nauplii and further to zebrafish via a trophic food web experiment: CYP1A induction and visual tracking of persistent organic pollutants. Environmental Toxicology and Chemistry. 2016; 35: 16561666.

[45] Giacomo AC, Stefania G, Massimo M, Maura B, Daniele F, Giuseppe DE, et al. Pollutants bioavailability and toxicological risk from microplastics to marine mussels. Environmental Pollution. 2015; 198: 211-222.

[46] Chen Q, Gundlach M, Yang SY, Jiang J, Velki M, Yin DQ, et al. Quantitative investigation of the mechanisms of microplastics and nanoplastics toward zebrafish larvae locomotor activity. Science of the Total Environment. 2017; 584-585: 1022-1031.

[47] Dris R, Gasperi J, Rocher V, Mohamed S. Microplastic contamination in an urban area: a case study in Greater Paris. Environmental Chemistry. 2015; 12: 592-599.

[48] Schymanski D, Goldbeck C, Humpf HU, Fürst P. Analysis of microplastics in water by micro-Raman spectroscopy: Release of plastic particles from different packaging into mineral water. Water Research. 2018; 129: 154-162.

[49] Yang DQ, Shi HH, Li L, Li JA, Khalida J, Prabhu K. Microplastic Pollution in Table Salts from China. Environmental Science \& Technology. 2015; 49: 13622-13627.

[50] Zhang Q, Xu EG, Li J, Chen QQ, Shi HH. A Review of Microplastics in Table Salt, Drinking Water, and Air: Direct Human Exposure. Environmental Science \& Technology. 2020; 54: 3740-3751.

[51] Wright SL, Kelly FJ. Plastic and Human Health: A Micro Issue? Environmental Science \& Technology. 2017; 51: 6634-6647.

[52] Prata JC. Airborne microplastics: Consequences to human health? Environmental Pollution. 2018; 234: 115-126.

[53] Anderson ASM, Kloas W, Zarfl C, Hempel S, Rillig MC. Microplastics as an emerging threat to terrestrial ecosystems. Global Change Biology. 2018; 24: 1405-1416.

[54] Bosker T, Bouwman LJ, Brun NR, Behrens P, Vijver MG. Microplastics accumulate on pores in seed capsule and delay germination and root growth of the terrestrial vascular plant Lepidium sativum. Chemosphere. 2019; 226: 774-781.

[55] Liu YY, Zhang Q, Cui WZ, Duan ZW, Wang FY. Toxicity of polyethylene microplastics to seed germination of mung bean. Environment and Development. 2019; 31: 123-125. (In Chinese)

[56] Lian JP, Shen MM, Liu WT. Effects of microplastics on wheat seed germination and seedling growth. Journal of AgroEnvironment Science. 2019; 38: 737-745. (In Chinese)
[57] Lian JP, Wu JN, Xiong H, Zeb A, Liu WT. Impact of polystyrene nanoplastics (PSNPs) on seed germination and seedling growth of wheat (Triticum aestivum L.). Journal of Hazardous Materials. 2020; 385: 121620.

[58] Wu JN, Yang TZ, Lian JP, Meng L, Wang N, Liu WT. Effects of polystyrene nanoplastics (PSNPs) on seed germination and seedling growth of soybean (Glycine max). Acta Scientiae Circumstantiae. 2020; 40: 4581-4589. (In Chinese)

[59] Xu G, Li FS, Wang QH. Effect of simulated acid rain on release of plasticizer in PVC film. Journal of Agro-Environment Science. 2006; 25: 1625-1630. (In Chinese)

[60] Liu XD, Gong YF, Li J, Xue JY, Wu F, Pan JX. Effects of plasticizers on programmed cell death during wheat seed germination. Journal of Triticeae Crops. 2013; 33: 350-356.

[61] Massos A, Turner A. Lead and bromine in beached microplastics. Environmental Pollution. 2017; 227: 139-145.

[62] Pascall MA, Zabik ME, Zabik MJ, Hernandez RJ. Uptake of polychlorinated biphenyls (PCBs) from an aqueous medium by polyethylene, polyvinyl chloride, and polystyrene films. Journal of Agricultural and Food Chemistry. 2005; 53: 164-169.

[63] Giorgetti L, Spanò C, Muccifora S, Bottega S, Barbieri F, Bellani $\mathrm{L}$, et al. Exploring the interaction between polystyrene nanoplastics and Allium cepa during germination: Internalization in root cells, induction of toxicity and oxidative stress. Plant Physiology and Biochemistry. 2020; 149: 170-177.

[64] Dris R, Gasperj J, Saad M, Mirande C, Tassin B. Synthetie fibers in atmospheric fallout: a source of microplastics in the environment. Marine Pollution Bulletin. 2016; 104: 290-293.

[65] Dris R, Gasperi J, Mirande C, Mandin C, Guerrouache M, Langlois $\mathrm{V}$, et al. A first overview of textile fibers, including microplastics, in indoor and outdoor environments. Environmental Pollution. 2017; 221: 453-458.

[66] Rillig MC, Lehmann A, Machado A, Yang G. Micro-plastic effects on plants. New Phytologist. 2019; 223: 1066-1070.

[67] Guo XT, Hu GL, Fan X, Jia H. Sorption properties of cadmium on microplastics: The common practice experiment and A twodimensional correlation spectroscopic study. Ecotoxicology and Environmental Safety. 2020; 190: 110118

[68] Anderson ASM, Wai LC, Jennifer T, Werner K, Anika L, Roland BR. Impacts of Microplastics on the Soil Biophysical Environment. Environmental Science \& Technology. 2018; 52: 9656 9665.

[69] Zhang X, Zheng M, Yin X, Wang L, Lou YH, Qu LY, et al. Sorption of 3,6-dibromocarbazole and 1,3,6,8-tetrabromocarbazole by microplastics. Marine Pollution Bulletin. 2019; 138: 458463.

[70] Lwanga EH, Gertsen H, Gooren H, Peters P, Tamas S, Martine VDP, et al. Incorporation of microplastics from litter into burrows of Lumbricus terrestris. Environmental Pollution. 2016; 220: 523-531. 